\title{
UN DIBUJANTE ERÓTICO: CRESCENCIANO GARZA RIVERA
}

XAVIER MOYSSÉN

Un artista punto menos que ignorado por la crítica actual, es Crescenciano Garza Rivera, autor de una obra extensa e interesante a juzgar por los dibujos que de él se conocen; dibujos singulares por su originalidad y por el tratamiento que dio a los temas eróticos de que se ocupa, los cuales le sitúan dentro de la corriente decadentista "Fin de siglo XIX", como se denomina a este tipo de expresiones.

Crescenciano Garza Rivera nació en Monterrey, N.L., el 14 de febrero de 1895; en la misma ciudad falleció el 3 de junio de 1958. Estudió pintura en la Academia de San Carlos; entre 1916 y 1921 vivió y viajó por España y Francia; en París asistió a la École des Beaux Arts, en tanto que en Madrid se relacionó con artistas y escritores de la época; fue amigo de Ramón del Valle Inclán, quien incluso lo protegió ayudándole para que expusiera sus dibujos en el Ateneo madrileño, exposición que fue comentada por críticos como José Francés, ${ }^{2}$ Ramón Gómez de la Serna y Manuel Abril, entre otros. Al retornar a México residió tanto en la capital del país como en Monterrey, en donde sus dibujos ilustraron las páginas de la revista Sueño. Durante siete años colaboró como dibujante de El Universal, bajo la dirección de Félix F. Palavicini. En su breve biografía, contenida en el diccionario citado, se asienta que residió también en Los Ángeles, Cal., y que expuso en San Antonio, Texas.

Respecto a sus actividades artísticas, se encuentran algunos retratos al óleo, más algunas pinturas murales que, se dice, realizó para la Casa del Campesino, en Monterrey;; también practicó el grabado al aguafuerte e hizo un buen número de dibujos para la prensa diaria, además de caricaturas. El primer comentario crítico que se escribió sobre su obra lo hizo A. Cantú Jáuregui en 1917; por su interés lo transcribo aquí:

\footnotetext{
${ }^{1}$ Noticias tomadas del Diccionario biográfico de Nuevo León, tomo I, Monterrey, México, Universidad Autónoma de Nuevo León, 1984.

${ }^{2}$ Con el título de "Garza Rivera, dibujante del misterio", José Francés publicó en México un artículo "inédito y exclusivo", en El Universal Ilustrado, que apareció el 9 de diciembre de 1920
} 
...por lo que respecta a "Sueño", tengo el orgullo de decir que en ella se han insertado los mejores dibujos de un artista regiomontano de gran porvenir, Garza Rivera, que ha estudiado en París, y que está llamado como Montenegro, a tener una bien conquistada fama mundial. Sus dibujos son audaces y originales, y su factura, si no perfecta aún, revela en su ejecutante a un futuro maestro, con el mismo estilo que tanto brillo cultivara Ruelas. ${ }^{3}$

En 1938 publicaron en Monterrey el libro titulado Fantasias de C. Garza Rivera, en el cual se reproducen cincuenta dibujos de él, y veintinueve artículos de escritores tanto de Europa como de América; entre estos últimos se encuentra Alfonso Reyes. El libro permite conocer a un fervoroso practicante del arte erótico posterior a Julio Ruelas, si bien con una personalidad propia.

Los dibujos publicados en el libro citado, algunos de los cuales se reproducen aquí, más otros que se encuentran en colecciones particulares, están realizados con pluma y tinta negra, predominando ésta en los densos fondos oscuros en los que sobresalen como motivo principal, los cuerpos blancos de hermosas mujeres, dignas representantes de la femme fatal. Son dibujos trazados con la mano firme que obedece a una idea sensual bien delimitada; vistos en conjunto guardan una distancia considerable del tipo creado por Julio Ruelas, o de las elegantes líneas de que gustó Roberto Montenegro en sus ilustraciones simbolistas, y aun de Carlos Neve; citarle junto a estos maestros del dibujo no es casual, es evidente que no escapó a las influencias de los tres, sobre todo tomando en cuenta que fue contemporáneo de los dos últimos; sin embargo, para definir bien su originalidad hay que estudiarle con las obras gráficas de los artistas simbolistas europeos que debió conocer durante sus años en Europa, entre otras las del belga Felicien Rops

La mujer para Crescenciano Garza Rivera, tiene el significado que es común en muchos de los decandentistas: la considera como la maldición fatal que puede aniquilar al hombre, de allí la presencia constante de la muerte al lado de la mujer." "La muerte y el amor. Los eternos y subyugantes motivos parecen ser la predilección del artista de Monterrey", escribió sobre él Miguel de Uranga. ${ }^{4}$ Determinantes fuentes de inspiración para Garza Rivera fueron las lecturas de Las flores del mal, de Charles Baudelaire, y El jardin de los suplicios, de Octave Mirbeau; sus dibujos son como ecos

\footnotetext{
${ }^{3}$ Cantú Jáuregui fue director de la Revista Sueño, y su comentario fue publicado bajo el título de "La intelectualidad en el resurgimiento de Nuevo León", en las páginas de $E l$ Universal Ilustrado, México, 24 de agosto de 1917

${ }^{4}$ En el libro Fantasias de C. Garza Rivera, sin paginación
} 
DOI: http://dx.doi.org/10.22201/iie.18703062e.1992.63.1647

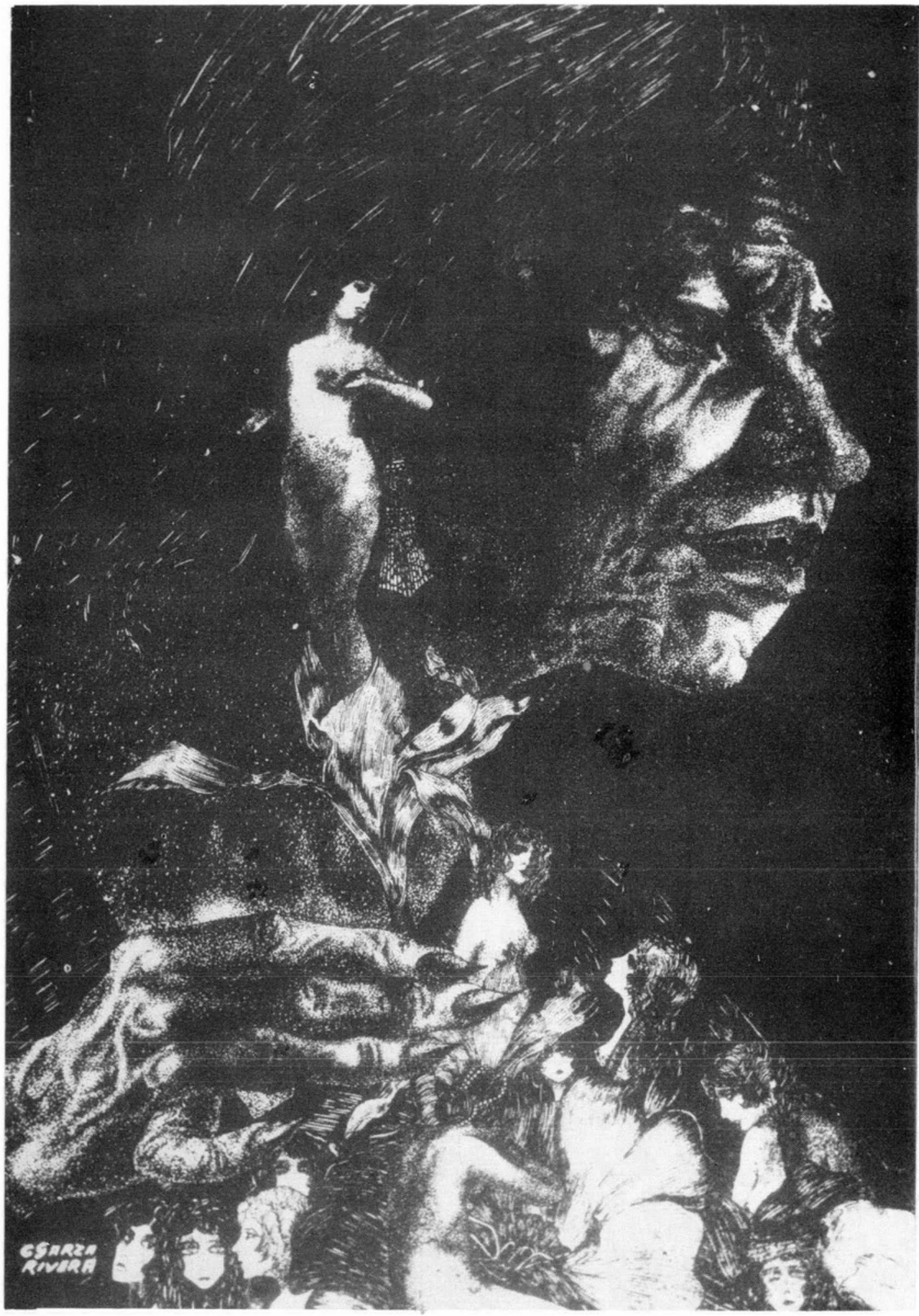

1. La vendedora de flores (las flores del mal). 


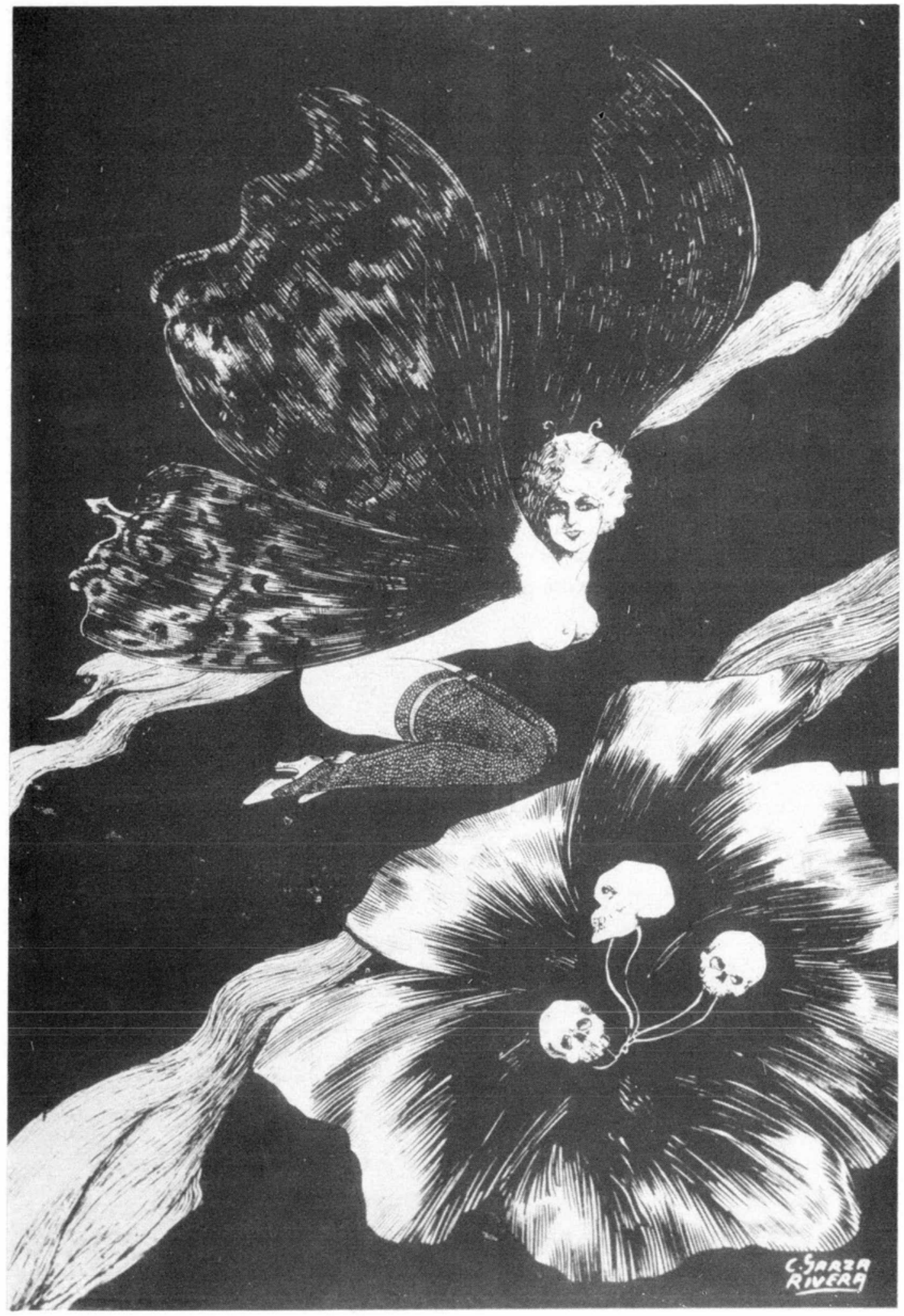

2. Indiferencia. 


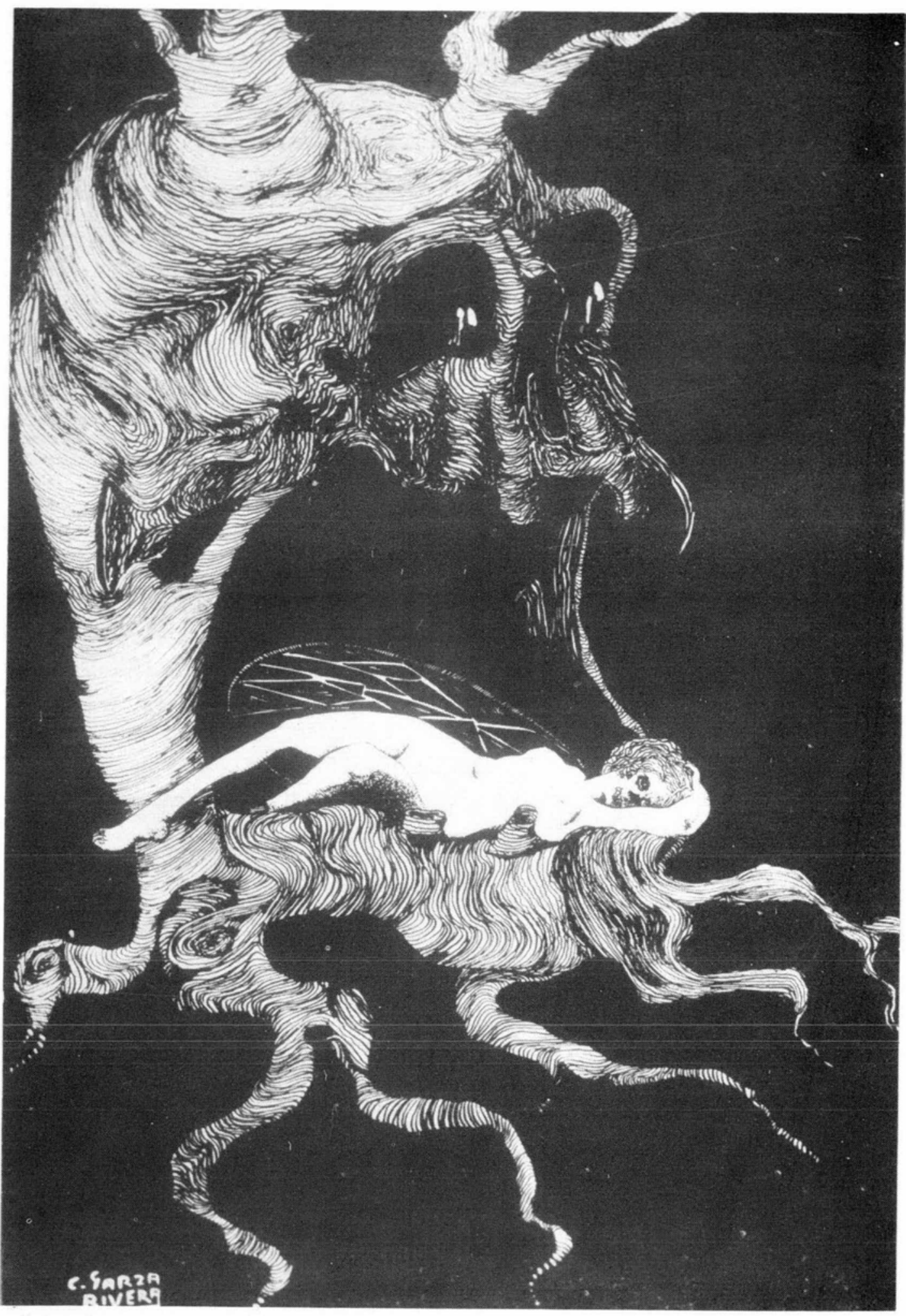

3. Imprevisión. 
DOI: http://dx.doi.org/10.22201/iie.18703062e.1992.63.1647

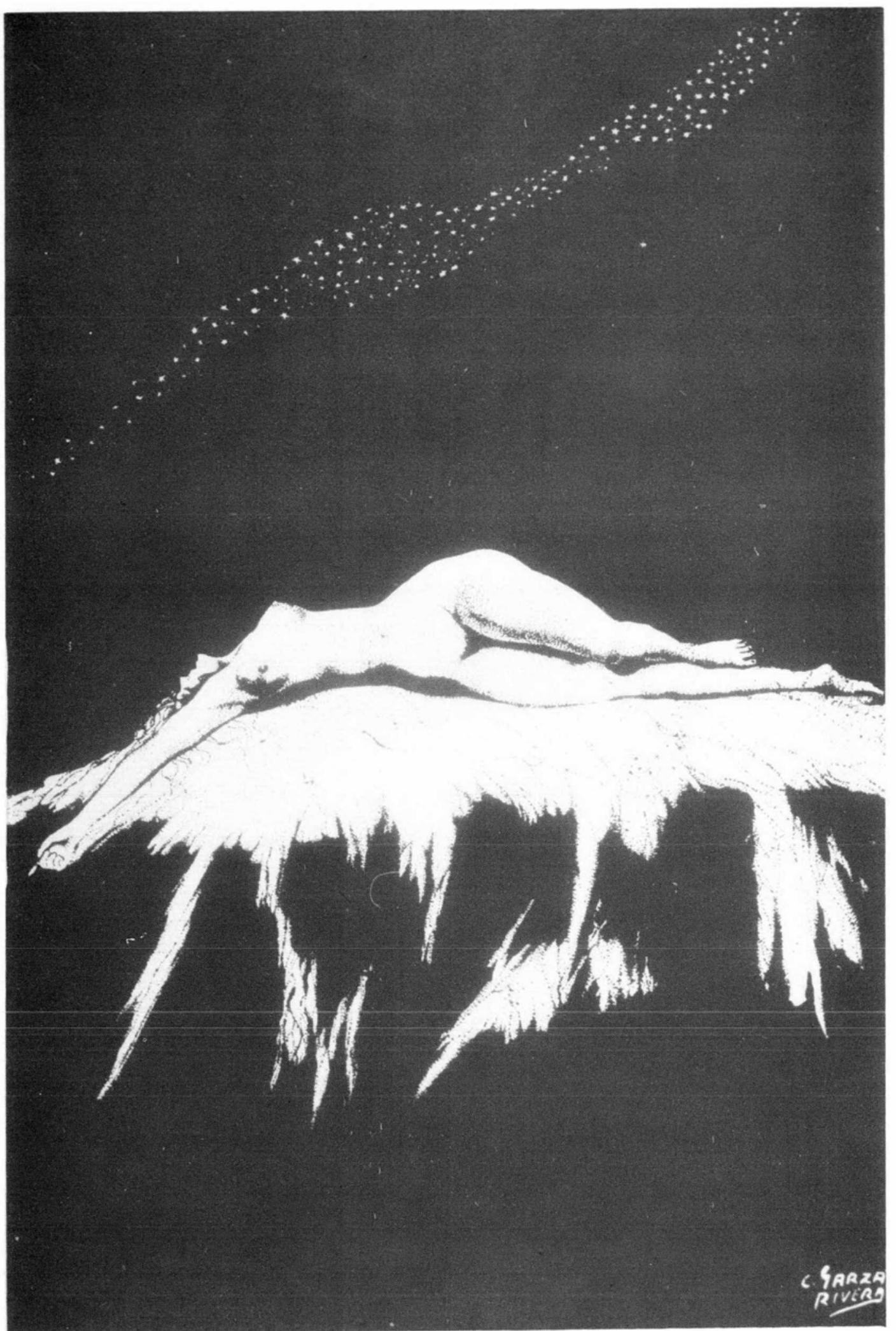




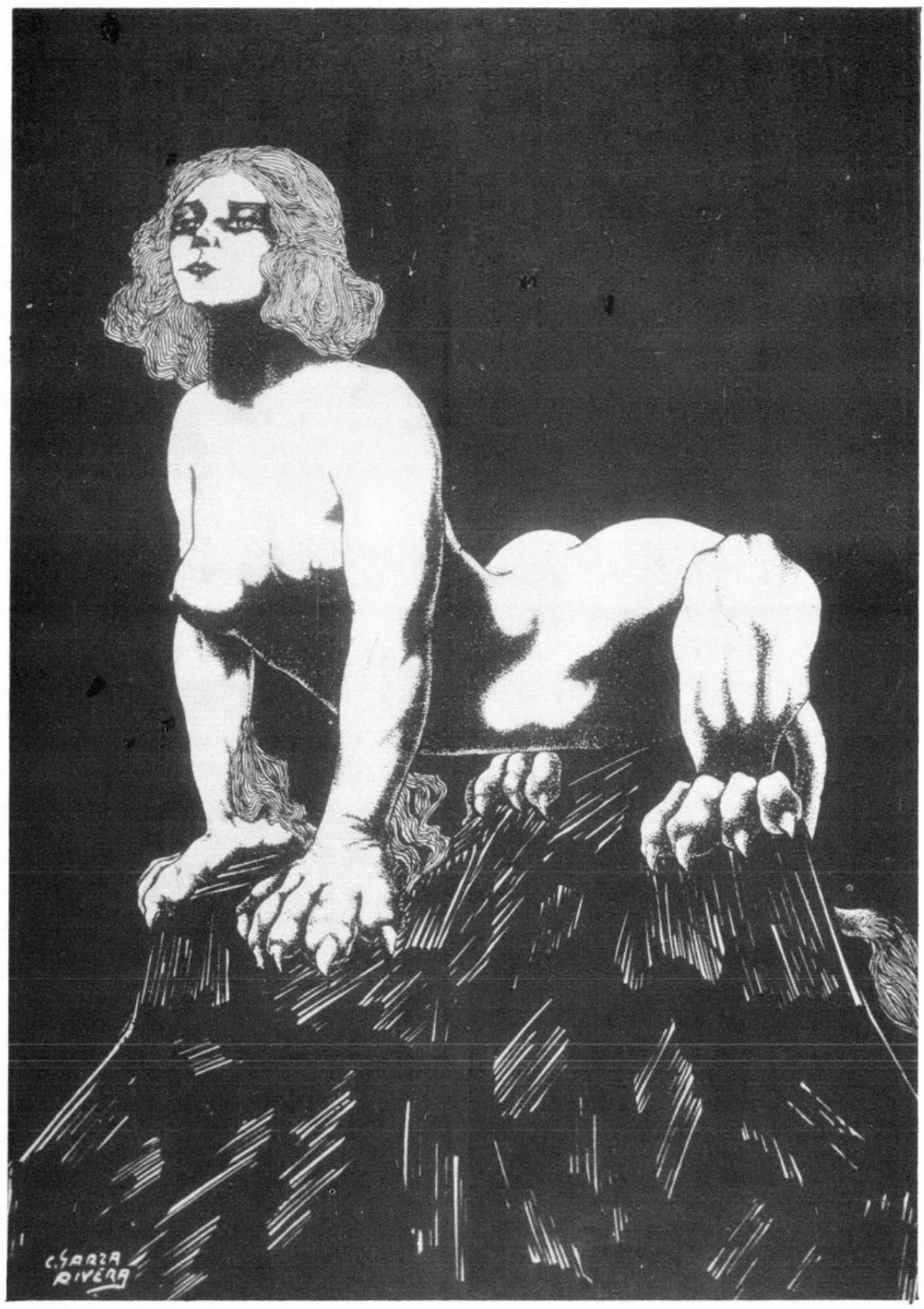

5. La esfinge. 


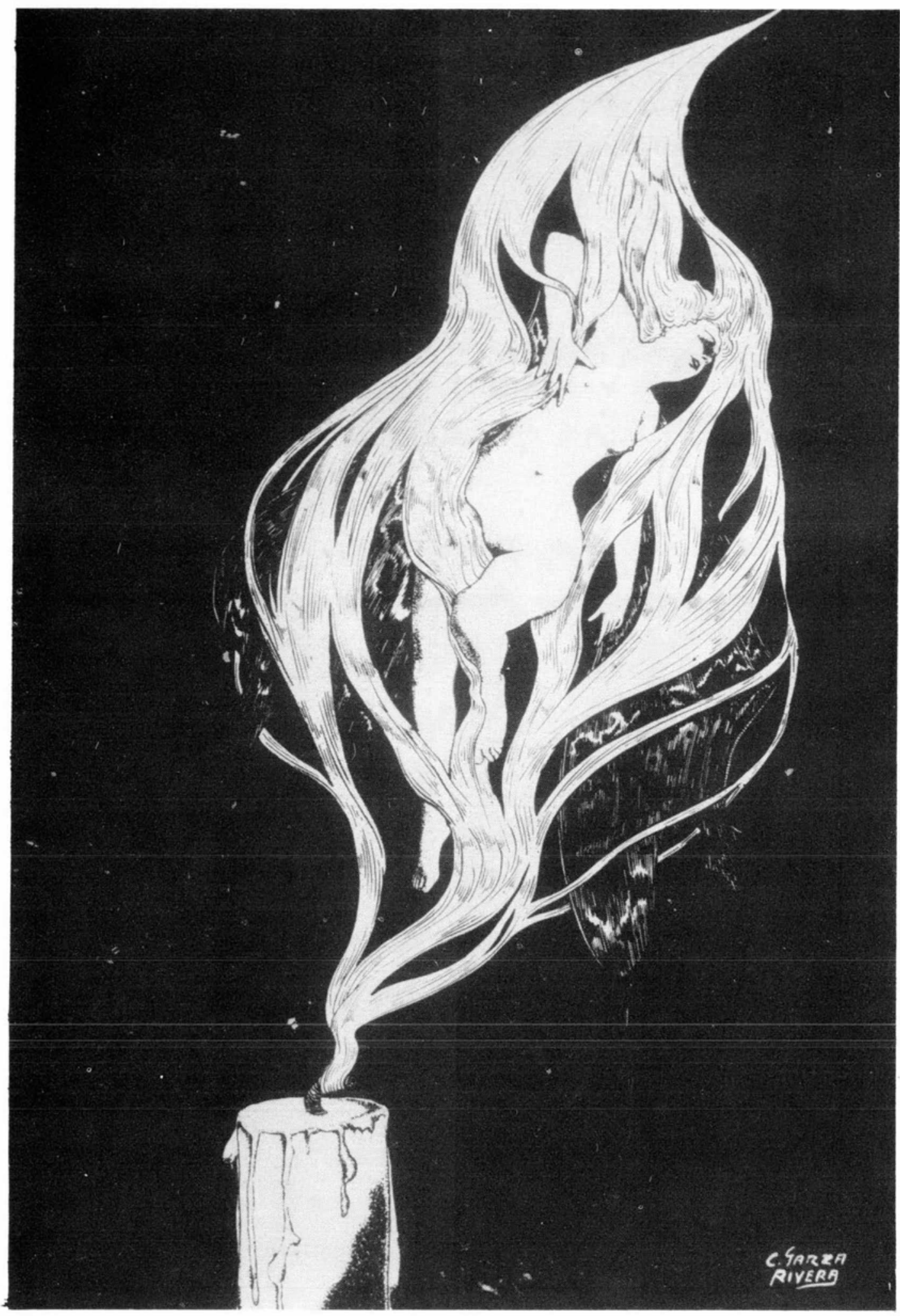

6. Ilusión muerta. 
DOI: http://dx.doi.org/10.22201/iie.18703062e.1992.63.1647
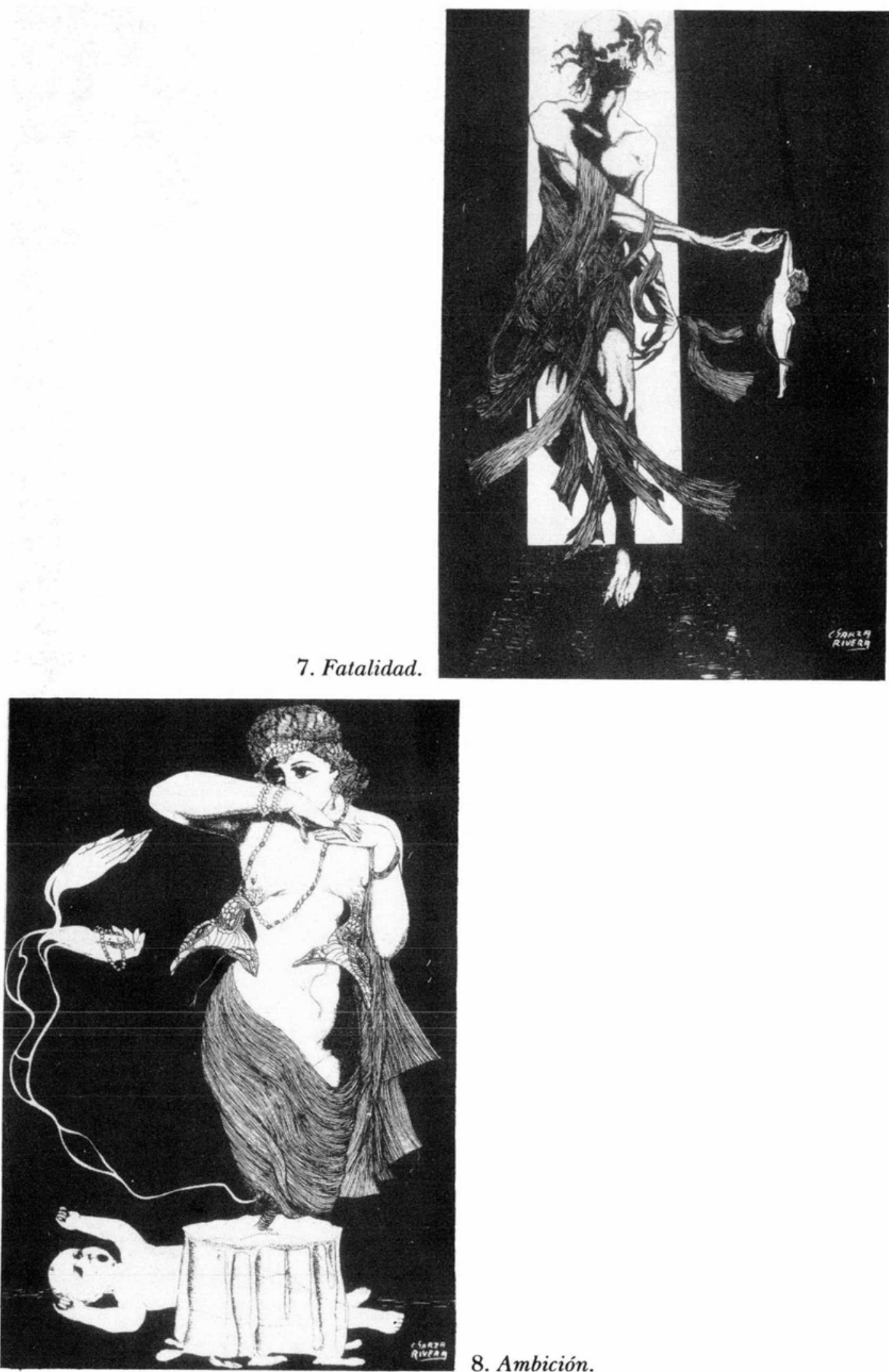

8. Ambición. 
DOI: http://dx.doi.org/10.22201/iie.18703062e.1992.63.1647

9. Miseria.
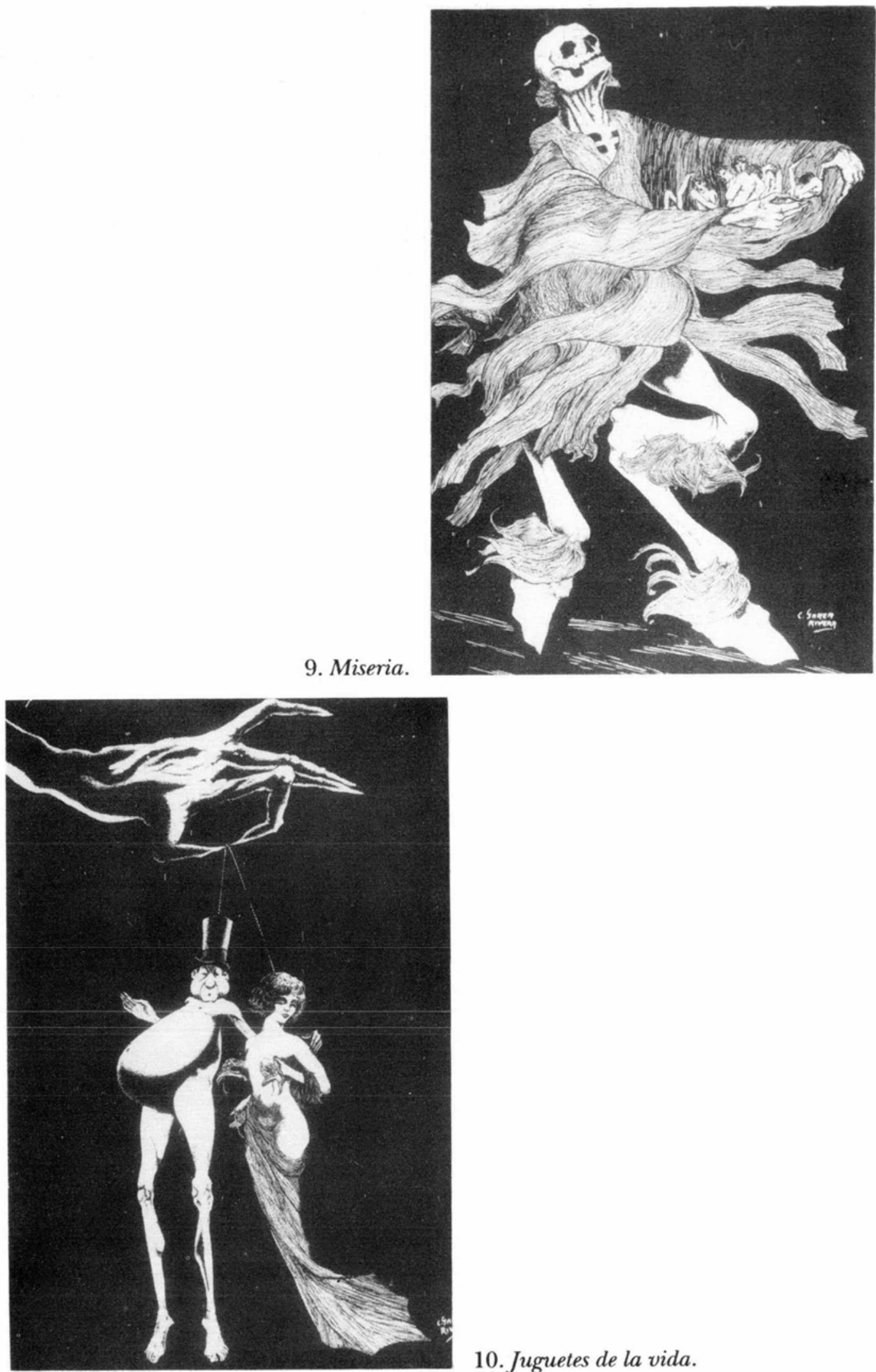

10. Juguetes de la vida. 
tardíos del decadentismo francés de fin de siglo. El simbolista español Emilio Carrere, que conoció al artista regiomontano en Madrid, tras ver su obra publicó lo siguiente: "...tiene gran talento para componer misteriosas alegorías. Sus dibujos son atrayentes con la fascinación de las tremendas liturgias voluptuosas. Su retina tiene la visión de una eterna misa negra, el sacrificio del diablo amarrado con sangre y con lujuria. Por eso es intensa y dislaceradamente (sic) humano en toda la grandeza horrible de su mágica fantasía...."

Las figuras simbólicas recurrentes en los dibujos de Garza Rivera, son la mujer desnuda, la muerte, las serpientes, los sátiros y el diablo, a las que se suman seres infantiles como víctimas inocentes de amores pasajeros. Una concepción enteramente negativa fue la que tuvo sobre la mujer; la representó en una dualidad, como la belleza en sí (figura 2), y como la muerte misma en las formas voluptuosas de su cuerpo, (figura 3). Llegó hasta la monstruosidad en el delirio que tuvo contra ella; en algunos dibujos los senos femeninos no son más que horrendas cabezas de feroces serpientes (figuras 8 y 10), en lo cual coincidió con el erotismo del poeta Efrén Rebolledo (1877-1929), quien en su soneto "El beso de Safo", se refiere a los senos de mujeres como pitones. ${ }^{6}$

La femme fatal, siempre ella; en algunas ocasiones la vio como desafiante, segura de su dominio sobre los hombres, como en La esfinge, (figura 5); en otras, como una graciosa y diabólica criatura con alas de mariposa, que deposita en las corolas de las flores los cráneos de sus víctimas; pero ella también depende de la muerte: las figuras 7 y 9 así lo indican, sobre todo la última, entrega una terrible imagen de la parca que, triunfante, transporta los cuerpos desnudos, irredentos, que sólo existen para los placeres de la carne.

Los dibujos de Grescenciano Garza Rivera constituyen una interesante aportación al arte erótico de México, su sitio está al lado de Julio Ruelas, Severo Amador y Carlos Neve, y de la "producción prohibida" de los grandes maestros, como José Clemente Orozco, de quien existe en una colección particular, una libreta con dibujos a lápiz de elevado tono erótico. Ojalá este breve estudio sobre el artista de Monterrey, logre motivar a sus paisanos para que investiguen y den a conocer aspectos de la obra del atormentado Garza Rivera.

\footnotetext{
${ }^{5}$ Idem.

${ }^{6}$ En Caro victrix, México, Imprenta de I Escalante, 1916
} 